\title{
Physical-Chemical Characterization and Nutritional Quality of Sesame Oil (Sesamum indicum L.).
}

\author{
Luciana de Almeida Vittori Gouveia ${ }^{*}$, Lilia Zago², Annie Seixas Bello Moreira ${ }^{2,3}$ \\ ${ }^{1}$ Nutritionist and Postgraduate Program of Food, Nutrition and Health/Nutrition Institute, Rio de Janeiro \\ State University, Rio de Janeiro, Brazil.
}

${ }^{2}$ Nutrition Institute, Rio de Janeiro State University, Rio de Janeiro, Brazil.

${ }^{3}$ Research Department, National Institute of Cardiology, Rio de Janeiro, Brazil.

Received: April 18, 2017; Accepted: April 24, 2017; Published: May 23, 2017

*Corresponding author: Luciana de Almeida Vittori Gouveia, Rua Manoel Pereira de Oliveira, 180, Chacrinha - Nova Iguaçu - Rio de Janeiro, Brasil, CEP: 26285600,E-mail: lucianavittori@yahoo.com.br

\begin{abstract}
The objective of this study was to analyze the physical and chemical characteristics of crude sesame oil (Sesamum indicum L.) and its nutritional quality. Determination of the fatty acid profile; of nutritional quality indexes (Atherogenicity Index (AI), Thrombogenicity Index (TI), the ratio between polyunsaturated fatty acids and saturated fatty acids (PUFA / SFA) and the Omega 6: omega 3 ratio); of the oil identity and quality standard (peroxide and acid indexes) and vitamin $\mathrm{E}$ were realized. The results were submitted to analysis of variance (ANOVA), with Tukey's post test to compare the averages between the groups. To compare only two groups, the t-test was used. The confidence interval was 95\%. The Graph Pad Prism 5 software was used. The results of the study showed that the fatty acid profile of crude sesame oil is in accordance with recommendations of Anvisa, being considered an important source of omega- 6 and omega-9. Regarding the nutritional quality indices, the values of AI and TI were 0.14 and 0.07 , respectively, considered low values that indicate that sesame oil can be considered beneficial to cardiovascular health. The acid and peroxide indexes are in accordance with the recommendations of Anvisa suggesting adequate standard of identity and product quality. The adequate peroxide content is indicative of the oxidative process, guaranteeing low oxidation, which can also be explained by the presence of vitamin E $(28.34 \mathrm{mg} / 100 \mathrm{ml}$ ) Concerning the clinical applicability, the consumption of sesame oil can be stimulated by the source of unsaturated fatty acids and vitamin $\mathrm{E}$, besides presenting indexes of nutritional quality and adequate identity and quality standards. However, other studies need to be performed in relation to nutritional quality.
\end{abstract}

Keywords: Sesamum; Sesame oil; Fatty acids; Nutritional Quality; Identity and Quality Standards; Vitamin E

\section{Introduction}

The sesame seed belongs to the family Pedaliaceae, it is cultivated in tropical and subtropical countries, basically by small farmers having its origin in the African and Asian continents.
Its main constituent is the oil that, depending on the type of cultivation and seed planting, can exceed $60 \%$ of its weight [2].

Sesame oil is defined, according to Resolution RDC No. 482, as "the edible oil obtained from Sesamum indicum $L$. seed by appropriate technological processes" and crude sesame oil is the "oil obtained by the extraction process" [3]. This process of extraction, according to Queiroga e Silva (2008), is carried out directly in the whole grains, by means of 4 steps: roasting of the grains, steam cooking, pressing and filtration [4].

It is known that sesame is an important source of oleic monounsaturated fatty acid, considered excellent oil $[4,5]$. It is known that there is a great influence in relation to its ingestion and quantity of the fatty acids on the health, mainly, in relation to the cardiovascular diseases [6], which are considered the main cause of death in the world, around 37\% [7]. Scientific evidence indicates that the increase in the consumption of unsaturated fatty acids present, for example, in vegetable oils is effective in preventing these diseases $[8,9]$. The combination of the beneficial fatty acid profile and the rich nutritional composition of the sesame oil makes it possible to be considered a quality food with excellent functional properties.

The objective of this work was to analyze the physical and chemical characteristics of crude sesame oil and its nutritional quality.

\section{Material and methods}

\section{Raw material: acquisition}

Crude sesame oil (Sesamum indicum L.) was acquired from natural product houses. The analyzes were carried out at the Laboratory of Bromatology of the Institute of Nutrition (INU) of State University of Rio de Janeiro (UERJ) and at CBO Laboratory in Campinas, São Paulo. 


\section{Physicochemical analysis}

Determination of the Fatty Acid Profile: The fatty acid profile was determined in triplicate by high resolution gas chromatography, according to the analytical methods of the associations of official analytical chemists [11]. Initially, the determination of ethereal extract was carried out by the Soxhlet method $[12,13]$, for further analysis of fatty.

Determination of nutritional quality indices: The nutritional quality of crude sesame oil was determined by fatty acid composition, taking into account the following indexes: atherogenicity index (AI) which considers saturated fatty acids as lauric, myristic as atherogenic and Unsaturated fatty acids as anti-atherogenic and palmitic; The Thrombogenicity Index (TI), which considers monounsaturated, polyunsaturated fatty acids as antithrombogenic and saturated fatty acids (myristic, palmitic and stearic) as thrombogenic [14]; the ratio between polyunsaturated fatty acids and saturated fatty acids (PUFA / SFA, according to London (1984) [15] and, also, the ratio of omega 6:omega

$A I=[(C 12: 0)+(4 \times C 14: 0)+(C 16: 0)+(C 16: 0)] /$ (PUFA n-6 + PUFA n-3 + MUFA), where C12: 0, C14: 0 and C16: 0, respectively, the saturated fatty acids lauric, myristic and palmitic; And PUFA n-6, PUFA n-3 and MUFA, respectively, omega- 6 and omega- 3 polyunsaturated fatty acids and monounsaturated fatty acids

$$
\text { IT }=(\text { C14:0 }+ \text { C16:0 + C18:0) } /[(0,5 \times \text { MUFA })+(0,5
$$
$\times$ PUFA n-6) + (3 $\times$ PUFA n-3) + (PUFA n-3 / PUFA n-6)], where C14: 0, C16: 0 and C18: 0 , respectively, myristic, palmitic and stearic acids; MUFA represents the sum of the concentrations of all monounsaturated fatty acids; PUFA n- 6 represents the omega- 6 polyunsaturated fatty acid and PUFA n- 3 represents the omega-3 polyunsaturated fatty acid [14].

Determination of the oil identity and quality standard: To determine the nutritional quality of crude sesame oil, acid and peroxide indices were analyzed to determine the oil identity and quality standard.

The determination of the acid index consisted of weighing $2 \mathrm{~g}$ of the sample, in an analytical balance model AW 220 , in triplicate, well homogeneous and completely liquid, in an Erlenmeyer flask of $125 \mathrm{~mL}$. Then, $25 \mathrm{~mL}$ of neutral ether-alcohol (2: 1) solution and 2 drops of the phenolphthalein indicator were added. The last step was titration with $0.1 \mathrm{M}$ sodium hydroxide solution until the appearance of pink coloration, persisting for 30 seconds. The analysis and calculation were carried out according to the Adolf Lutz Institute [16] and Resolution RDC 482/1999 of the National Agency of Sanitary Surveillance [3], which determines the acidity index for crude sesame oil in g of oleic acid / $100 \mathrm{~g}$.

Acidity in oleic acid = v x f x M x 28.2 / P, where,

$\mathrm{V}=$ number of $\mathrm{mL}$ of sodium hydroxide solution $0.1 \mathrm{M}$ spent in the titration.
$\mathrm{F}=$ correction factor of sodium hydroxide

$\mathrm{P}=$ sample g number

The determination of the peroxide index was performed according to the analytical norms of Adolfo Lutz Institute [16]. $5 \mathrm{~g}$ of the sample was weighed in an AW 220 analytical balance in triplicate in a $250 \mathrm{~mL}$ Erlenmeyer flask and $30 \mathrm{~mL}$ of 3: 2 acetic-chloroform solution was added and shaken until complete dissolution of the sample. Then, $0.5 \mathrm{ml}$ of the potassium iodide (KI) saturated solution was added and the sample was allowed to stand out from the light for exactly 1 minute. $30 \mathrm{~mL}$ of water was added and finally the titration was carried out with $0.01 \mathrm{~N}$ sodium thiosulphate solution, with constant stirring until the yellow color had almost disappeared. Then $0.5 \mathrm{ml}$ of indicator starch solution was added and the titration continued until the complete disappearance of the blue coloration. A blank test was prepared under the same conditions quoted and titled at the end.

Peroxide content in meq per $1000 \mathrm{~g}$ of the sample $=(A-B) \times \mathrm{N} x \mathrm{f}$ x 1000 / P, where:

$A=m L$ number of $0.01 \mathrm{~N}$ sodium thiosulphate solution spent on sample titration

$\mathrm{B}=\mathrm{mL}$ number of the $0.01 \mathrm{~N}$ sodium thiosulfate solution used in titration of the blank

$\mathrm{N}=$ normality of sodium thiosulphate solution

$\mathrm{F}=$ factor of sodium thiosulphide solution

$\mathrm{P}=$ sample $\mathrm{g}$ number

Determination of Vitamin E: The alpha-tocopherol type of vitamin E was determined by HPLC (High Performance Liquid Chromatography) in a single analysis [17].

\section{Statistical analyzes}

The results were submitted to analysis of variance (ANOVA), with Tukey's post test to compare the means between the groups. To compare only two groups, the t-test was used. The confidence interval was 95\%. The GraphPad Prism 5.

\section{Results and discussion}

Table 1 shows the fatty acid profile of crude sesame oil, which is in accordance with the recommendations recommended by Anvisa [3], with the exception of stearic acid, which presented a lower value than that recommended in the legislation that allows this saturated fatty acid to be up to $6 \mathrm{~g} / 100 \mathrm{~g}$, and therefore not considered relevant to our study. The alphalinolenic unsaturated fatty acid presented values higher than those recommended by the legislation. The oil is considered an important source of polyunsaturated fatty acid linoleic (omega-6), oleic monounsaturated fatty acid (omega-9) and small amount of polyunsaturated fatty acid linolenic (omega-3). In relation to saturated fats, the palmitic and stearic acids are those found in greater amounts.

On the effects of saturated fatty acids on the lipid profile and on cardiovascular risk factors, it is known that 
lauric fatty acid may increases LDL-c, as well as myristic fatty acid. This meta-analysis also showed that stearic fatty acid may cause small reduction in LDL-c [18]. The first fatty acid was not found in crude sesame oil and the second in small quantities in all products and in sesame oil, presented within the recommended by the legislation [3]. Another study found $14.59 \%$ of lauric acid in sesame oil [19]. However, sesame as well as other vegetable oils did not present lauric acid in their composition [20]. Antoniassi et al. (2013) analyzed sesame oil in different regions and did not present lauric acid data [21].

\section{Table 1: Fatty acid profile of Crude Sesame Oil}

Table 1: Fatty acid profile of Crude Sesame Oil

\begin{tabular}{|c|c|c|}
\hline Fatty acid profile & $\begin{array}{c}\text { Sesame oil } \\
\text { (\%) }\end{array}$ & $\begin{array}{c}\text { g/100g } \\
\text { (RDC/482) }\end{array}$ \\
\hline Ethereal extract & $99,71 \pm 0,18$ & UE \\
\hline Saturated fatty acid & \multicolumn{2}{|l|}{} \\
\hline Caprylic (C 8:0) & $0,02 \pm 0,00$ & UE \\
\hline Myristic (C 14:0) & $0,04 \pm 0$ & $<0,5$ \\
\hline Palmitic (C 16:0) & $11,49 \pm 0,04$ & $7,0-12,0$ \\
\hline Margaric (C 17:0) & $0,05 \pm 0,00$ & UE \\
\hline Stearic (C 18:0) & $2,64 \pm 0,01$ & $3,5-6,0$ \\
\hline Arachidonic (C 20:0) & $0,52 \pm 0,01$ & $<1,0$ \\
\hline Behenic (C 22:0) & $0,23 \pm 0,01$ & $<0,5$ \\
\hline Ticosanic (C 23:0) & $0,04 \pm 0,00$ & UE \\
\hline Lignoceric (C 24:0) & $0,22 \pm 0,00$ & UE \\
\hline Total (Saturated fatty acid) & 15,25 & \\
\hline & &
\end{tabular}

\begin{tabular}{|c|c|c|}
\hline \multicolumn{3}{|c|}{ Monounsatured fatty acids } \\
\hline Palmitoleic (C 16:1) & $0,14 \pm 0,01$ & $<0,5$ \\
\hline Oleic (C 18:1) & $35,32 \pm 0,27$ & $35,0-50,0$ \\
\hline Erucico (22:1 n9c) & $0,02 \pm 0,00$ & $\mathrm{NE}$ \\
\hline $\begin{array}{c}\text { Total (Monounsaturated } \\
\text { fatty acid) }\end{array}$ & 35,48 & \\
\hline
\end{tabular}

\begin{tabular}{|c|c|c|}
\hline \multicolumn{2}{|l|}{ Polyunsaturated fatty acids } \\
\hline Linoleic (C 18:2) & $47,62 \pm 0,19$ & $35,0 / 50,0$ \\
\hline Alpha-linolenic (C 18:3) & $1,25 \pm 0,05$ & $<1,0$ \\
\hline Eicosenoic (C 20:1) & $0,25 \pm 0,01$ & $<0,5$ \\
\hline Cys-Eicosadienoic (C 20:2) & $0,01 \pm 0,01$ & $\mathrm{NE}$ \\
\hline $\begin{array}{c}\text { Total (Polyunsaturated } \\
\text { fatty acids) }\end{array}$ & 49,13 & \\
\hline
\end{tabular}

Mean \pm Standard Deviation; UE $=$ unspecified *Resolution RDC No. 482 of September 23, 1999 (BRAZIL, 1999)

Antoniassi et al. (2013) analyzed the fatty acid profile of sesame oil from two different regions, Patos, in Paraíba and in Bartalha, no Ceará and found higher values than those found in our study for stearic fatty acid, being 5.36\%, in Patos and 5,74\% in Bartalha, and for palmitic acid, 10\%, in the two analyzed regions [21]. In relation to the effects of saturated fatty acids on the lipid profile and cardiovascular risk factors, it is known that lauric fatty acid may increases LDL-c, as well as myristic fatty acid. This meta-analysis also showed that stearic fatty acid may cause small reduction in LDL-c [18]. Stearic acid is present in sesame oil, according to the results presented in our study.

Guimarães et al. (2013) observed that sesame oil has a higher concentration of saturated palmitic fatty acid compared to stearic saturated fatty acid [19]. In relation to unsaturated fatty acids, sesame oil is richer in oleic monounsaturated fatty acid and polyunsaturated fatty acid linoleic (omega-6). Comparing these results with those found in our study, we found higher values of oleic fatty acid $(35.32 \%)$ compared to $28.59 \%$ of linoleic acid, we found $47.62 \%$, while Guimarães et al. (2013) found a lower value than ours (28.35\%) [19]. we found that sesame oil has a low content of alpha-linoleic acid (1.25\%) in our study.

According to the I Guideline on fat consumption and cardiovascular health, (2013), dietary factors are related to the incidence of cardiovascular diseases, mainly in relation to the consumption of different types of fat, since they interfere in the appearance or not of atherosclerotic events. It is known that consumption of saturated and trans fat is related to elevated LDL-C levels and increased cardiovascular risk, whereas the presence of mono and polyunsaturated fats in the diet is important for the control of hypercholesterolemia and consequently, reduce the chances of cardiovascular events [22].

This way, fatty acids can promote or prevent the onset of atherosclerosis, according to the effects on serum cholesterol levels and Low-Density Lipoprotein (LDL) concentrations. In this context, it is suggested as a measure to verify the influence of diet on the incidence of cardiovascular diseases, atherogenicity index (AI) and Thrombogenicity Index (TI). AI considers the saturated fatty acids lauric, myristic and palmitic in relation to unsaturated fatty acids; TI considers myristic (C14: 0), palmitic (C16: 0) and stearic (18: 0) saturated fatty acids as thrombogenic and polyunsaturated fatty acids omega 3 and monounsaturated fatty acids with antithrombogenic effects [14]. These indices may indicate the nutritional quality of oils and fats and their possible benefits or harm to cardiovascular health, since they indicate the potential for stimulating platelet aggregation [23].

Crude sesame oil had AI of 0.14 and TI of 0.07 (Table 2). Guimarães et al. (2013) found values of the AI and TI indexes in sesame oil of 0.69 and 0.13 , respectively [19]. Ulbricth and Southgate (1991) reported the following TI values in different types of vegetable oils: 6.18 in coconut oil, 1.74 in palm oil and 0.32 in olive oil [14]. In relation to AI, the crude sesame oil analyzed in this study was considered zero value related to lauric acid, since no saturated fatty acid was detected in our study and, according to other studies, it was also not found in the fatty acid profile of sesame oil [20, 21]. Guimarães et al. (2013) found $14.59 \%$ of lauric fatty acid in the sesame oil analyzed in their study [19]. 
Crude sesame oil presented low values in relation to the indices of nutritional quality (AI and TI), and can therefore be considered an oil that offers cardiovascular health benefits. According to Turan, et al. (2007), lower values of AI and TI indicate that there is a greater amount of anti-atherogenic and antithrombogenic fatty acids in the oil or fat and, therefore, may be considered an important food in the prevention of cardiovascular diseases [23]. These elevated indices are considered risk factors for cardiovascular diseases and when food presents values lower than 1, they may present cardio protective effects [24].

The ratio between PUFA and SFA was 3.22. According to London (1984), values up to 0.45 are considered inadequate, since they are related to the higher increase in cholesterol levels [15]. In the present study, therefore, the value of 3.22 is considered excellent, showing that crude sesame oil has nutritional quality because it has a higher number of polyunsaturated fatty acids when compared to the amount of saturated fatty acids, according to what is reported by London [15]. Guimarães et al. (2013) found 0.79 in PUFA / SFA ratio in sesame oil [19]. This value is lower than our present study, but also considered adequate in relation to cardiovascular health.

Another important data regarding the polyunsaturated fatty acids in sesame and that analyzes its nutritional quality is the ratio omega- 6 / omega- 3 found in the oil that was 38 (Table 2 ), since the sesame is rich in omega- 6 and has little amount of omega-3.

This relationship is reported by the I Guideline on Fat Consumption and Cardiovascular Health, which discusses the role of this relationship in the diet on cardiovascular diseases, since it is considered a lot of controversy 22. Due to significant changes in diet in relation to intake of fatty acids, there was increased consumption of cereals, grains and oils sources of omega 6, besides a reduction in the consumption of food sources of omega 3 fatty acids. Of 15: 1 to 40: 1 in western feed [25, 26]. Santos et al (2013) report that this increase would make the formation of inflammatory factors related to obesity, diabetes and cardiovascular diseases higher [22]. However, if there is substantial evidence on the one hand side of the relationship between increased consumption of omega-3 source foods and cardiovascular protection, on the other hand, there is no scientific evidence that reducing omega- 6 , alone, would make the risk of cardiovascular disease decrease [27]. In addition, both fatty acids have cardiovascular health benefits and are considered essential fatty acids $[6,28]$.

Table 2: Nutritional quality of crude sesame oil

Table 2: Nutritional quality of crude sesame oil

\begin{tabular}{|l|l|}
\hline Perfil de ácidos graxos & óleo de gergelim \\
\hline Atherogenicity index (AI) & 0,14 \\
\hline Thrombogenicity index (AI) & 0.07 \\
\hline PUFA:SFA ratio & 3,22 \\
\hline $\mathbf{\omega 6}: \mathbf{\omega 3}$ ratio & 38 \\
\hline
\end{tabular}

It's important to highlight that although sesame is richer in omega 6 than in omega 3, it is a food rich in oleic monounsaturated fatty acid. Diets containing monounsaturated fatty acids make LDL less susceptible to oxidation and may result in inhibition of the atherogenic process [29]. A systematic review and meta-analysis of epidemiological studies and randomized controlled trials showed that adherence to dietary pattern, such as the Mediterranean diet, has cardiovascular protection effects and it is known that this diet is characterized by high consumption of monounsaturated fatty acids [30].

According to the recommendations of the I Guideline on fat consumption and cardiovascular health, the consumption of saturated, monounsaturated and polyunsaturated fats should be $<7 \%, 20 \%$ and $6 \%$ to $10 \%$, respectively, of the total caloric value of the diet [22]. DRIs recommend the daily intake of essential fatty acids linoleic, from 14 to $17 \mathrm{~g}$ for men and 11 to $12 \mathrm{~g}$ for women, and linolenic $1.1 \mathrm{~g}$ for women and $1.6 \mathrm{~g}$ for men [31].

Table 3 shows that the values obtained for the acid and peroxide indices are in accordance with the recommendations for crude sesame oil recommended by Resolution RDC n. 482 of September 23, 1999 of Anvisa [3], suggesting an adequate standard of identity and product quality of the present study.

Table 3. Identity and quality standards of Crude Sesame 0il.

\begin{tabular}{l|l|l|}
\hline \multicolumn{3}{|c|}{ Table 3: Identity and quality standards of Crude Sesame Oil. } \\
\hline & $\begin{array}{l}\text { Crude Sesame } \\
\text { Oil }\end{array}$ & RDC/482* \\
\hline Acid Index (g oleic acid/100g) & $0,92 \pm 0,09$ & Maximum 2,0 \\
\hline Peroxide Index (meq/Kg) & $8,99 \pm 0,98$ & Maximum 10
\end{tabular}

Mean \pm Standard Deviation. *Resolution RDC No. 482 of September 23, 1999 of Anvisa

According to RDC Resolution No. 482 of September 23, 1999 [3], sesame oil is "the edible oil obtained from Sesamum indicum L. seed by appropriate technological processes" and crude sesame oil is the "oil obtained by the extraction process". The oil that was analyzed in this work is characterized as raw, cold-pressed, unrefined and extra-virgin sesame oil, according to manufacturer's information. The process of extraction of this type of oil, according to Queiroga and Silva (2008) is carried out directly in the whole grains, by means of 4 steps: roasting of the grains, steam cooking, pressing and filtration.

In relation to the results presented in this study, the sesame oil presented an excellent pattern of identity and quality [3], suggesting that this one presents greater conservation, low rancification and adequate oxidative stability.

Lipid oxidation can cause deterioration and loss of product quality, resulting in unpleasant flavors and odors for food, as well as changes in nutritional quality, color, aroma and texture. This process can cause degradation of fat-soluble vitamins and essential fatty acids, in addition to affecting the integrity of the 
food product, making it unfit for consumption [32, 33]. Some external compounds such as light, temperature and storage time also interfere in this quality [34].

Therefore, this guarantee of oxidative stability found in crude sesame oil is very important. The appropriate peroxide index, which is the important indicator of the oxidative process, and with values within what is recommended by Anvisa [3], will guarantee the quality of the oil.

It is suggested that this low oxidation of sesame oil can be explained by the presence of vitamin $\mathrm{E}$ found in the oil in our study, which was $28.34 \mathrm{mg} / 100 \mathrm{~mL}$. In relation to vitamin E, it is known that this is an important nutrient in relation to the antioxidant defense [35], being responsible for inhibiting or reducing the damage caused by reactive oxygen species (ROS) [36].

Thus, sesame oil may be associated with the improvement of oxidative stress as shown by some scientific evidence [8]. Guinaz et al. (2009) analyzed the vitamin E content in vegetable oils and observed that canola oil had the highest alpha-tocopherol content (18.39 mg / $100 \mathrm{~mL}$ ) when compared to soybean oil (12.14 mg / $100 \mathrm{~mL}$ ) and extra-virgin olive oil (14.05 mg / $100 \mathrm{~mL}$ ) [37]. Our findings found $28.34 \mathrm{mg} / 100 \mathrm{~mL}$ of vitamin E in sesame oil, showing that it has a higher content of vitamin $\mathrm{E}$ when compared to the vegetable oils analyzed by Guinaz et al. [37]. It is known that antioxidant chemicals are added to vegetable oils in order to inhibit or retard their lipid oxidation. The most common synthetic antioxidants used by the food industry are: BHA, BHT, PG and TBHQ and, among natural antioxidants, tocopherols are the most widely used [33]. The crude sesame oil used in this work had no increase in natural or synthetic antioxidants, according to the product label information.

In a study that evaluated the antioxidant activity of sesame extract of sesame oil in soybean and sunflower oil, it was observed that this reduced significantly the peroxide index in the studied vegetable oils, besides indicating that low concentrations of sesame extract presented better antioxidant effect when compared to the use of BHT [38].

According to the clinical trials that used sesame oil in their populations, the recommendation of daily consumption would be $35 \mathrm{~g}$ per day in order to obtain beneficial effects to human health $[39,40,41,42]$. This amount would represent $2+$ $1 / 2$ tablespoons of raw sesame oil, measured in our study, which has $9.92 \mathrm{mg}$ of vitamin E, which corresponds to $66.13 \%$ of the daily recommendation of this vitamin. Is $15 \mathrm{mg} /$ day for men and women [43]. Thus, we can say that sesame oil is a source of vitamin $\mathrm{E}$, since the legislation determines that reaching at least $15 \%$ of the DRI of vitamin, the product is considered source of this nutrient [44].

In a study with vegetable oils, sesame oil presented greater oxidative stability when compared to flaxseed oil [19], which may have as an explanation the presence of natural antioxidants, such as sesamin, sesamol and sesamolin, which are specific sesame's lignans $[45,5]$, which ensure higher stability to unsaturated fatty acids [2], in addition to high antioxidant activity [46].

Moazzami et al. (2006) analyzed the lignan content in seeds and sesame oil and observed that the main components are sesamin (8.80 mg / g seed and $6.20 \mathrm{mg} / \mathrm{g}$ oil) and sesamolin ( $4.50 \mathrm{mg} / \mathrm{g}$ of seed and $2.45 \mathrm{mg} / \mathrm{g}$ of oil), without significant differences between the white and black seed according to the authors [47].

Due to the high content of this fatty acid and the presence of natural antioxidants, such as vitamin E and lignans, sesame is considered an oil that is more resistant to oxidation and low rancification $[4,5]$.

\section{Conclusion}

Sesame oil had important nutritional quality indexes in relation to cardiovascular health, since AI and IT were low and the ratio between PUFA and SFA was considered adequate when compared to other studies. In addition, the sesame oil presented an identity and quality standard in compliance with the legislation, with adequate peroxide and acidity indexes, indicating that it is a kind of oil with good oxidative stability and low rancification.

Regarding the clinical applicability, the consumption of sesame oil could be stimulated by an important source of unsaturated fatty acids and vitamin E according to the observed results. Clinical trials with sesame already showed their effects on lipid profile, blood pressure and oxidative stress. The results of these studies can be explained by the composition of unsaturated fatty acids present in sesame and the content of insoluble fibers. In addition, the concentration of vitamin $\mathrm{E}$ in sesame oil makes it work in the improvement of oxidative stress, avoiding or decreasing the formation of ROS and assisting in the improvement of the lipid profile. Other studies need to be performed in relation to nutritional quality indexes, as there are still few studies that analyze the rates of atherogenicity and thrombogenicity.

\section{References}

1.Ricci AB, Groth D, Lago AA. Density of plants, drying and production of sesame seeds cv. IAC-China. Revista Brasileira de Sementes. 1999;21(1):82-86.

2.Beltrão NEM, Vieira, DJ. The agribusiness of sesame in Brazil. Brasília: Embrapa Information Technology. 2001;p.348.

3.Brazil. Ministry of Health. National Sanitary Surveillance Agency. Resolution RDC n 482, September 23, 1999. Approving the Technical Regulation for Oils and Fat Identification and Quality Fixation. 1999.

4.Queiroga VP, Silva ORRRF. Technologies used in the cultivation of mechanized sesame. Embrapa-National Cotton Research Center, Campina Grande. Documents 203. 2008;p.142.

5. Queiroga VP, Duran JM, Santos JW, Queiroga DAN. Effect of cotton seed coating on its physiological quality. Brazilian Journal of Oilseeds and Fibers. 2007;11(3):131-137

6.Lands B. A critique of paradoxes in current advice on dietary lipids. Prog 
Lipid Res. 2008;47(2):77-106. doi: 10.1016/j.plipres.2007.12.001.

7.WHO. World Health Organization, 2016. Available from: http://www. who.int/mediacentre/factsheets/fs317/en/ Acess in: January 3, 2017

8.Gouveia LAV, Cardoso CA, Oliveira GMM, Rosa G, Moreira ASB. Effects of the Intake of Sesame Seeds (Sesamum indicum L.) and Derivatives on Oxidative Stress: A Systematic Review. Journal of Medicinal Food. 2016;19(4):337-345. doi: 10.1089/jmf.2015.0075.

9.Cardoso CA, Oliveira GMM, Gouveia LAV, Moreira ASB, Rosa G. The effect of dietary intake of sesame (Sesamum indicum L.) derivatives related to the lipid profile and blood pressure: a systematic review. Crit Rev Food Sci Nutr. 2016. doi: 10.1080/10408398.2015.1137858

10.Zoumpoulakis P, Sinanoglou VJ, Batrinou A, Strati IF, Meimaroglou SM, Sflomos K. A combined methodology to detect c-irradiated white sesame seed sand evaluate the effects on fat content, physicochemical properties and protein allergenicity. Elsevier: Food Chemistry. 2012;131:713-721.

11.AOAC. Associations of official analytical chemists. Official Methods of Analyses of the Association of Analytical Chemists. 18 ed, 2005. method 996.06; 20-25

12. AOAC. Association of official analytical chemists. Official methods of analysis of the Association of Analytical Chemists. Arlington: AOAC cap. 33. (method 920.39, C). 1995; p.10- 11.

13. Adolfo Lutz Institute. Analytical Standards of the Adolfo Lutz Institute. Chemical and physical methods for food analysis. 4th ed. Sao Paulo. 2005;p.118-119.

14. Ulbricht TLV, Southgate DAT. Coronary heart disease: seven dietary factors. Lancet. 1991;338(8773):985-992. doi: doi.org/10.1016/01406736(91)91846-M

15.London. Department of Health and Social Security. Diet and cardiovascular disease. London: HMSO. 1984;p.28.

16. Adolfo Lutz Institute. Physico-Chemical Methods for Analysis of Foods. 4th ed. IV, 2008.

17.MEP Analysis and Quality. Basic method for the Determination of tocopherol and vitamin E acetate via HPLC. Basf, 2004:p.4.

18. Micha R, Mozaffarian D. Saturated fat and cardiometabolic risk factors, coronary heart disease, stroke, and diabetes: a fresh look at the evidence. Lipids. 2010;45(10):893-905. doi: 10.1007/s11745-0103393-4

19. Guimarães RCA, Macedo MLR, Munhoz CL, Filiu W, Viana, LH, Nozaki VT, et al. Sesame and flaxseed oil: nutritional quality and effects on serum lipids and glucose in rats. Food Sci. Technol, Campinas. 2013;33(1):209217. doi: doi.org/10.1590/S0101-20612013005000029

20. Oliveira MF, Vieira OV. Extração de óleos de girassol utilizando miniprensa EMBRAPA. 2004;p.30 (Documents n. 237)

21.Antoniassi R, Arriel NHC, Gonçalves ER, Freitas, SC, Zanotto DL, Bizzo HR. Influence of the culture conditions on the composition of the seeds and the sesame oil. Rev CeresViçosa. 2013;60(3):301-310.
22.Santos RD, Gagliardi ACM, Xavier HT, Magnoni CD, Cassani R, Lottenberg AM, et al. I Guideline on the consumption of fats and cardiovascular health. Arq Bras Cardiol. 2013;100(1 suppl 3):1-40.

23. Turan H, Sönmez G, Kaya Y. Fatty acid profile and proximate composition of the thornback ray (Raja clavata, L. 1758) from the Sinop coast in the Black Sea. Journal of Fish Science. 2007;1(2):97103. doi: $10.3153 /$ jfscom. 2007012

24. Ramos Filho MM, Maria Isabel Lima Ramos; Priscila Aiko Hiane; Elizabeth Maria Talá de Souza. Lipid profile of four species of fish from the Pantanal region of Mato Grosso do Sul. Food Science and Technology. 2008;28(2):361-365. doi: doi.org/10.1590/S010120612008000200014

25. Simopoulos AP. The importance of the ratio of omega-6/ omega-3 essential fatty acids. Biomed Pharmacother. 2002;56(8):365-379.

26. Simopoulos AP. Evolutionary aspects of diet, the omega-6/ omega-3 ratio and genetic variation: nutritional implications for chronic diseases. Biomed Pharmacother. 2006;60(9):502- 507. doi: 10.1016/j. biopha.2006.07.080

27. Harris WS, Mozaffarian D, Rimm E, Kris-Etherton P, Rudel LL, Appel LJ, et al. Omega-6 fatty acids and risk for cardiovascular disease: a science advisory from the American Heart Association Nutrition Subcommittee of the Council on Nutrition, Physical Activity, and Metabolism; Council on Cardiovascular Nursing; and Council on Epidemiology and Prevention. Circulation. 2009;119(6):902-907. doi: 10.1161/CIRCULATIONAHA.108.191627

28. Liou YA, Ling DJ, Zibrik D, Innis SM. Decreasing linoleic acid with constant alpha-linolenic acid in dietary fats increases (n-3) eicosapentaenoic acid in plasma phospholipids in healthy men. J Nutr. 2007;137(4):945-952.

29. Reaven PD, Grasse BJ, Tribble DL. Effects of linoleate-enriched and oleate-enriched diets in combination with alpha-tocopherol on the susceptibility of LDL and LDL subfractions to oxidative modification in humans. Arterioscler Thromb. 1994;14(4):557-566. doi: doi. org/10.1161/01.ATV.14.4.557

30. Kastorini CM, Milionis HJ, Esposito K, Giuliano D, Goudevenos JÁ, Panagiotakos DB. The effect of Mediterranean diet on metabolic syndrome and its components: a meta-analysis of 50 studies and 534,906 individuals. J Am Coll Cardiol. 2011;57(11):1299-1313. doi: 10.1016/j.jacc.2010.09.073.

31. IOM. Institute of Medicine: DRI. Dietary Reference Intakes for Energy, Carbohydrate. Fiber, Fat, Fatty Acids, Cholesterol, Protein, and Amino Acids. 2005

32.Buckley DJ, Morrisey PA, Gray JL. Influence of dietary vitamin E on the oxidative stability and quality of pig meat. J Anim Sci. 1995;73(10):3122-3130. doi:10.2527/1995.73103122x

33.Ramalho, VC, Jorge N. Antioxidants used in oils, fats and fatty foods. Quim. Nova. 2006;29(4):755-760. Doi: doi.org/10.1590/S010040422006000400023 
34.Batista ES, Costa AGV, Pinheiro-sant'ana HM. Adding vitamin E to foods: implications for the foods and for human health. Nutr Campinas. 2007;20(5):525-535. doi: doi.org/10.1590/S141552732007000500008

35.Bianchi MLP, Antunes LMG. Free radicals and the main antioxidants in the diet. Rev Nutr. 1999;12(2):123-130. doi: doi.org/10.1590/S141552731999000200001

36.Koury JC, Donangelo CM. Zinc, oxidative stress and physical activity. Rev. Nutr.Campinas. 2003;16(4): 433-441.

37.Guinaz M, Milagres RCRM, Pinheiro-Sant'ana HM, Chaves, JBP. Tocopherols and tocotrienois in vegetable oils and eggs. Química Nova. 2009;32(8):2098-2103.

38.Suja KP, Abraham JT, Jayalekshmy A, Arumughan C. Antioxidant efficacy of sesame cake extract in vegetable oil protection. Food Chemisty. 2004;84(3):393-400.

39.Sankar D, Rao R, Samdandam G, Pugalendi KV. Modulation of blood pressure, lipid profiles and redox status in hypertensive patients taking different edible oils. Clinica Chimica Acta, Índia. 2005;355(12):97-104. doi: 10.1016/j.cccn.2004.12.009

40. Sankar D, Rao R, Samdandam G, Pugalendi KV. A pilot study of open label sesame oil in hypertensive diabetics. Journal of Medicinal Food. 2006a;9(3):408-412. doi: 10.1089/jmf.2006.9.408
41.Sankar D, Rao R, Samdandam G, Pugalendi KV. Effect of sesame oil on diuretics or beta-blockers in the modulation of blood pressure, anthropometry, lipid profile, and redox status. Yale Journal od Biology and Medicine, Índia. 2006;79(1):19-26.

42.Sankar D, Ali A, Sambandam G, Rao R. Sesame oil exhibits synergistic effect with anti-diabetic medication in patients with type 2 diabetes mellitus. Clinical Nutrition, Índia. 2011;30(3):351-358. doi: 10.1016/j. clnu.2010.11.005

43.Iom. Institute of medicine. Dri: Dietary Reference Intakes for Vitamin C, Vitamin E, Selenium, and Carotenoids, 2000.

44.BRAZIL. Ministry of Health. National Sanitary Surveillance Agency. Resolution - RDC n 54, November 12, 2012. About the Technical Regulation about Complementary Nutritional Information. 2012.

45. Pathak N, Rai AK, Kumari R, Bhat KV. Value addition in sesame: A perspective on bioactive components for enhancing utility and profitability. Phramacogn Rev. 2014;8(16):147-155. doi: 10.4103/0973-7847.134249

46.Namiki M. Nutraceutical Functions of Sesame: A Review. Critical Reviews in Food Science and Nutrition. 2007;(7):651-673

47.MoazzamiAA, Andersson RE, Kamal-Eldin A. HPLC analysis of sesaminol glucosides in sesame seeds. J Agric Food Chem. 2006;54(3):633-638. doi: 10.1021/jf051541g 